\title{
SHARING INFORMATION IN SUPPLY CHAIN BETWEEN CONSTRUCTION COMPANIES AND THEIR MATERIAL SUPPLIERS
}

\author{
Nguyen Thi Van $\mathrm{Ha}^{1 *}$ and Tran Quang Bang ${ }^{1}$ \\ ${ }^{1}$ University of Transport and Communication
}

\begin{abstract}
Sharing information in supply chain between construction companies and their material suppliers has been ignored in Vietnam construction industry and a few reasearch has addressed this topic. The purpose of this paper is to analyze the importance of sharing information in strategic collaboration between construction companies and their material suppliers in supply chain. The author developed measurement scale of strategic collaboration and sharing information between construction companies and their material suppliers based on literature review and research gaps. The author mainly used quantitative research methodology through survey with questionnaire to explore research objectives. The results indicated that strategic collaboration is the trend of stakeholders in construction supply chain, especially between construction contractors and their material suppliers. The paper analyzed and evaluated the importance of strategic collobration and sharing information will contribute to improving awareness of construction companies related to supply chain management.
\end{abstract}

Keywords: Supply Chain, Strategic Collaboration, Information Sharing, Construction Industry, Supply Chain Management

\section{Introduction}

The term of supply chain management is originally proposed with the objectives of designating a new form of strategic logistics management [1,2]. The phenomena of cross-organizational integration named "the logistics of supply chain" have been fully developed through the popularity of Supply Chain Management (SCM) since the end of the 1990s [3]. The SCM addresses new issues of the full complexities of the design, planning, operation, and control of value chains and networks that extend beyond individual enterprises and their immediate suppliers and customer relationships [4]. The most critical point of supply chain management is the development of collaborative approach with the increased importance of inter-functional, inter-instrumental, and inter-organizational integration [2].

Collaboration has a variety of definitions and names but is generally treated as meaning the cooperative way that two or more entities work together toward a shared goal. Collaborative interactions among businesses as a profit strategy and models of the dynamics of those relationships have been explored in the business management and networking literature. Additionally, some researchers have explored the specific nature of successful relationships within business partnerships [5,6]. Collaboration among organizations in specialized industries such as electronic - electric industry and garment - textiles industry, the alliance most typically seen by evaluators, has become a key issue in research. However, a comprehensive theory of collaboration within the types of construction enterprises and their suppliers has not been studied profoundly and not been presented in the literature.

The General Statistics Office (GSO) reported that in 2016, the construction value reached $\$ 47.3$ billion, an increase of 10.1 percent over 2015. Most of the fields in the real estate industry had growth in the year and are expected to continue to grow, as the retail market continues to perform better (though the vacancy rate has 
remained at $10 \%-12 \%$ ). The reason for this high growth rate is that construction activity in 2016 was driven by stable materials prices, low interest rates, and improved real estate markets.

According to statistics of Vietnam Ministry of Construction (MOC), the total number of enterprises operating in the fields of construction sector is 68.649 (46.500 construction firms, 2829 companies producing building materials, 12.681 construction consultancy and investigation companies and 6639 real estate companies). In the early years of the 21 st century, Vietnam construction industry, one of the key sectors contributing to the relatively high gross domestic product (GDP) with the contribution of about $5 \%-7 \%$, has much contribution to economic development. Many construction enterprises have self-movement, corporate restructuring and reengineering, and better integration with partners in the business process to enhance business efficiency. However, construction companies have been facing some issues during their business operation, for example the case of collaboration between construction companies and their material suppliers.

There are several extensive difficulties regarding the supply chain of material, which involves the influence of their business operation. For example, the large flow of material in the construction industry is a challenge both for contractors and suppliers in order to create a cost optimized process. The material cost stand for between $40-45 \%$ of the total construction cost which further highlights the density of managing the flow of material. The construction site is generally a crowded and limited area where a lot of material is stored in an unorganized manner, which leads to costs concerning e.g. damage, theft and waste. In the past, the collaboration between construction companies and their material suppliers was regarded as shortage of adaptability and suitability because they do not focus on strengthening technical, IT, time related, legal, knowledge-based and social bonds. This may lead to the inefficient business results of construction firms.

Therefore, doing research on trends of strategic collaboration between construction companies and their material suppliers will make significant contribution to exploring different levels of strategic collaboration. If Vietnamese construction enterprises have firm and effective collaboration with their suppliers, the identification of responsibilities, duties, benefits, and collaboration is really clear, and then cost risks can be reduced and cost saving possibility is a matter of course. Among activities of strategic collaboration, sharing infomration plays an important role because it helps construction companies and their partners proceed the tasks easily and quickly. So it lead to the questions related to how the current sitution of strategic collaboration and information sharing between construction companies and their material suppliers is. Therefore, hypotheses include two main items:

+ Hypothesis 1: Strategic collaboration between construction companies and their material suppliers have strong level of importance in construction business

+ Hypothesis 2: Inforamation sharing between construction companies and their material suppliers have strong level of importance in construction business

The next parts include some contents related to literature review of theories and perspectives of strategic collaboration in construction industry; research methodology and design; research findings related to strategic collaboration and information sharing between construction companies and their material suppliers; conclusions and recommendations.

\section{Research Methodology}

Research design follows quantitative research methodology. Quantitative research was carried out through conducting questionnaire survey, collecting data, and running descriptive statistics based on data collected and coded by SPSS. All data was scanned, tested and analyzed to show collaboration practices between construction enterprises and their suppliers. Survey method is also employed to understand the current practices of collaboration in supply chain. Sharing resources/information and trends of strategic alliance in supply chain among partners has been still regarded as a growing scientific field that falls short of empirical research, 
especially survey method. Still, survey methodology is proved a valuable research tool to approach several layers of the extended supply chain.

This study conducted survey with the samples of 625 enterprises in relation to the size of the population in the field of construction in the North of Vietnam. The authors contacted with contractors (primary contractors, subcontractors) to conduct survey. Enterprises were selected from some province such as Hanoi, Bac Ninh, Thai Nguyen, Nam Dinh, Thai Binh, Hoa Binh, Vinh, Nghe An. The table below is the statistics information related to the number of enterprises that the author sent the questionnaire.

Table 1: The number of enterprises that were sent questionnaire to for surveying

\begin{tabular}{|l|l|l|}
\hline No & Provinces & Number of enterprises \\
\hline & Ha Noi & 189 \\
\hline & Bac Ninh & 64 \\
\hline & Thai Nguyen & 68 \\
\hline & Nam Dinh & 44 \\
\hline & Thai Binh & 65 \\
\hline & Hoa Binh & 75 \\
\hline & Vinh & 63 \\
\hline N & Nghe An & 57 \\
\hline Total & & 625 \\
\hline
\end{tabular}

Research objects are the construction businesses with diverse forms of relationships with suppliers. There are a couple of reasons for choosing these firms. Firstly, they (general contractors and sub-contractors) have provided various types of construction works including civil construction, transport construction, industrial construction, irrigation construction, and technical construction. Secondly, sizes of these businesses are ranging from small, medium to large based on the number of employees and the amount of business working capital. Thirdly, objects include enterprises with different forms of collaboration with material suppliers.

We selected these province to conduct our study because they are developing provinces with high growth rate. Therefore, the need and demand for construction and building has been still increasing.

\section{Results And Discussions}

\section{To profile background characteristics of respondents in survey}

Using the secondary resource from public domain of Ministry of Construction, the database of the study is established with a sample frame of 625 companies with the following characteristics:

- construction companies located in North of Vietnam

- $\quad$ of medium and large size according to Vietnam criteria, and

- doing business in the construction industry as project owners, main and subcontractors

We received 146 valid responses and used them in the analysis. This survey obtained the response rate of nearly $24.3 \%$. The response rate of this survey was little bit low in comparison between total sample and total respondents.

Among them, 24 firms are state-owned construction companies (16.4\%) and 86 firms are joint stock Construction companies (58.9\%). 15.1\% of respondents (22 companies) completing the questionnaire are from 
limited construction companies. Only 8 private construction companies (5.5\%), and 3 FDI construction companies involved in replying the questionnaire. Otherwise, 3 companies didn't not state their business type. Many of them are joint stock companies and limited companies (74\%), indicating that the trend of privatization in construction industry in Vietnam. The trend also helps companies in construction industry have more freedom to make collaboration together (Figure 1).

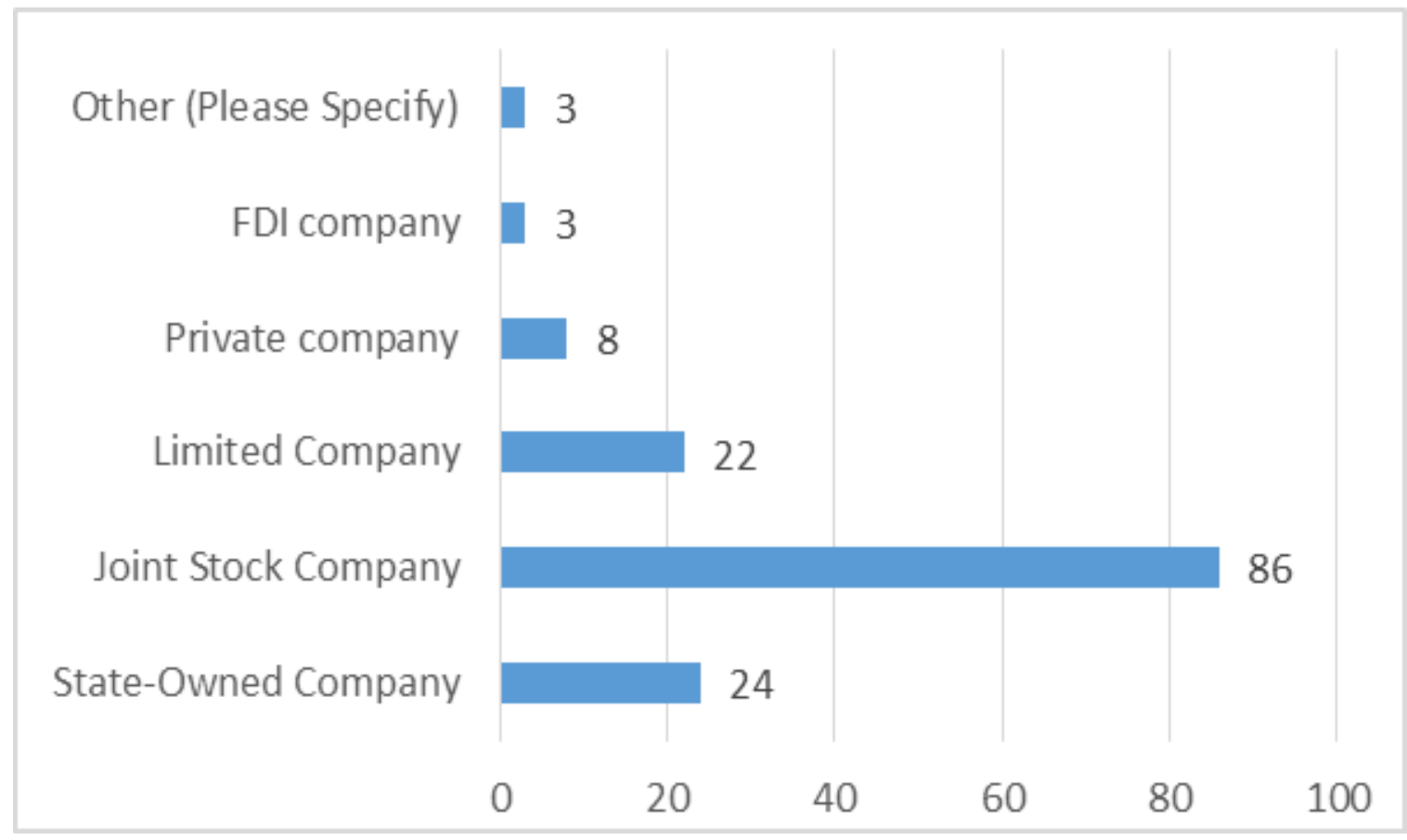

Figure 1: Types of Construction Companies

Respondent companies dealing with building and constructing different types of works. Among them, 51.8\% companies build civil construction (114 companies) in construction industry. For industrial and irrigation construction, approximately 72 companies deal with this construction, accounted for nearly 53\%. Only 18 companies are working with transport construction, accountd for $13.1 \%$. The rest ones (7.3\%), around 16 companies are implementing technical construction works.

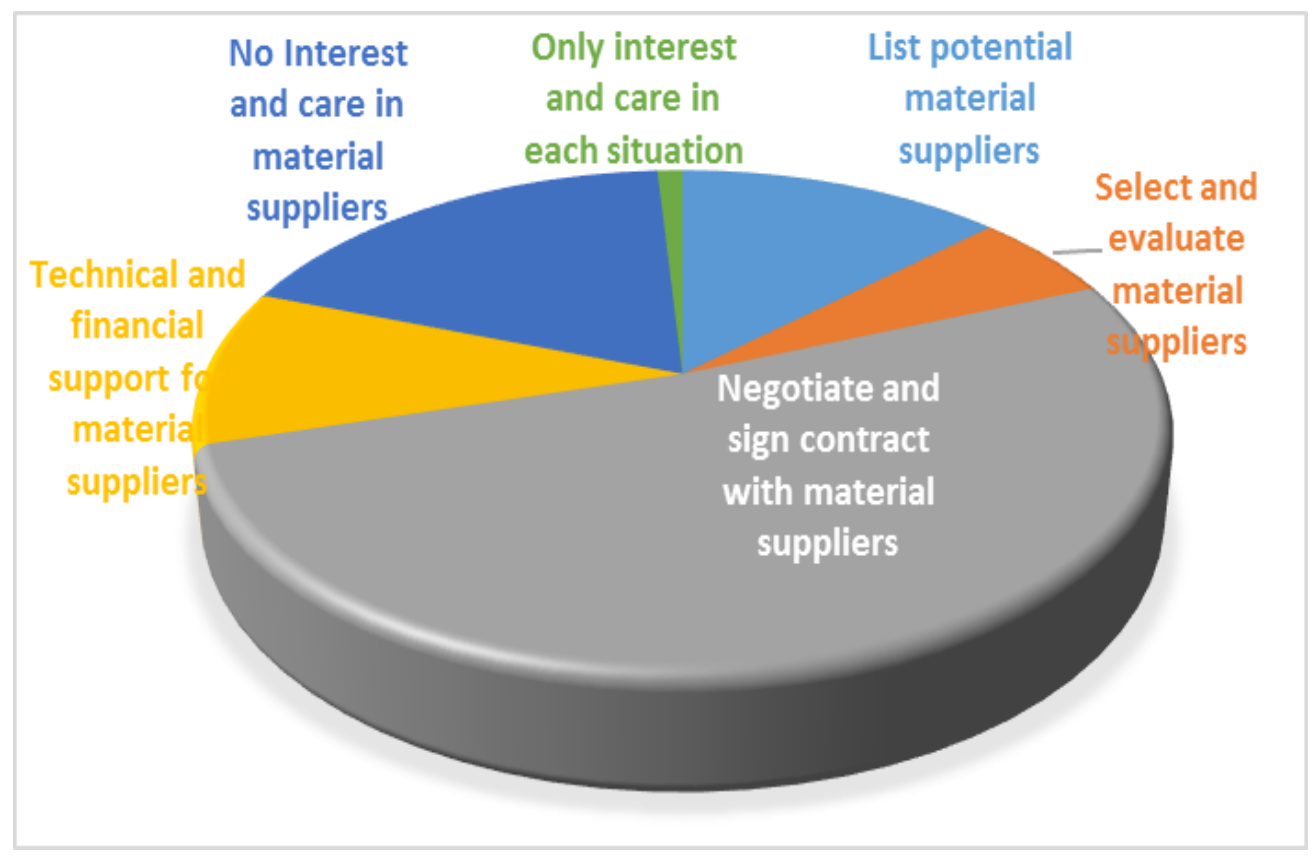


Figure 2: Ways of Managing and Controlling material suppliers

Construction companies have also managed and controlled material suppliers following different steps and processes. For example, in the questionnaire the author asked them 6 steps for managing and controlling material suppliers. According to Figure 2, 27 respondent companies selected the work of listing potential material suppliers (equivalent to 13\%). Meanwhile, only 12 respondent companies selected and evaluated their material suppliers (equivalent to 5.8\%). Many companies implemented step of negotiating and signing contract with material suppliers (51.7\%, equivalent to 107 responses). Some companies (27 responses, equivalent to $13 \%$ ) have the lists of potential material suppliers for them to select. Not so many companies have programs for technical and financial support for material suppliers (21 responses, equivalent to $10.1 \%$ only). It means that relationships with material suppliers have not been closed and firm enough for them to support and share resources. Surprisingly, 38 respondent companies (equivalent to 18.4\%) have no interests in and care of material suppliers. In their viewpoints, if material suppliers can supply materials with good quality, good price and good delivery following their demand, they can accept and make order with them without signing long-term contract or long term collaboration.

\section{Evaluating the level of importance of strategic collaboration and information sharing between construction companies and their material suppliers in supply chain}

In order to calculate important level of information sharing in strategic collaboration. The authors calculated the important level for each observed variables in information sharing and strategic collaboration by multiplying the frequency and the important scale (from 1 to 5).

Firstly, we calculated for all items in strategic collaboration, and finaly determine the average weighted mean for overall latent variable of strategic collaboration. We got the strong level of importance for average weighted mean of strategic collaboration, confirming the first hypothesis. Table 2 presents the results of important level of strategic.

Table 2. Importance of strategic collaboration

\begin{tabular}{|l|l|l|}
\hline $\begin{array}{l}\text { Measurement items } \\
\text { (Scale 1-5) }\end{array}$ & Mean & $\begin{array}{l}\text { Qualitative } \\
\text { Interpretation }\end{array}$ \\
\hline 1. SC1:Maintain short term collaboration through supply contracts & 3.93 & Important \\
\hline $\begin{array}{l}\text { 2. SC2: Maintain long term collaboration through frame supply contract } \\
\text { and specific annexes }\end{array}$ & 4.02 & Important \\
\hline $\begin{array}{l}\text { 3. SC3: Establish strategic alliance in long term supply: information } \\
\text { share and integration }\end{array}$ & 4.40 & Strongly Important \\
\hline $\begin{array}{l}\text { 4. SC4: Establish strategic alliance in long term supply: sharing and } \\
\text { supporting information, financial resources, capital investment }\end{array}$ & 4.31 & Strongly Important \\
\hline $\begin{array}{l}\text { 5. SC5: Establish strategic alliance in long term supply: merger and } \\
\text { acquisition, joint venture }\end{array}$ & 4.01 & Important \\
\hline Average weighted mean & 4.14 & Important \\
\hline
\end{tabular}

According to the results, strategic collaboration between construction companies and their material suppliers come from the lowest level of collaboration (SC 1: Short term collaboration and supply contract) to the highest level of collaboration (SC 4: strategic alliance with sharing and supporting financial resources and capital investment; SC 5: strategic alliance with merger and acquisition, joint venture). Many construction companies indicated that establishing strategic alliance in long term supply by sharing financial resources and capital investement (4.31) plays an extremely important role in developing their business. Especially, establishing strategic alliance in long term supply: sharing and supporting information, financial resources, capital investment (4.40) get the most important role in respondent companies'viewpoints. Meanwhile, the way of maintaining short term collaboration through supply contracts has not got Construction companies are 
nowadays looking for strategic partners with more long-term, sustainable and strategic collaboration because they collaborate based on trust,

commiment and share. Therefore, they have more opportunities to develop their business.

However, the trends of strategic collaboration with resource sharing has lower level of agreement than information sharing. Therefore, the author investigatged the evaluation of construction companies related to sharing information with their material suppliers in construction supply chain.

Activities of information sharing have not been accepted and implemented popularly between construction companies and their material. Almost respondents comapnies agreed to share information but with average level (average weighted mean 3.25 - 3.45). It indicated that from the thinking and viewpoints of strategic collboration to the action and implementation has been still difficulties and obstacles. For example, the difficulties may arise from the mindset, viewpoints of openess and sharing information, the fear of losing information, the worries of reducing the competitiveness, etc.

Among activities of sharing information, only the activities of sharing information related to demand forecasting (3.45) and exchanging information related future demand, direction and strategy (3.44) have the highest important level from the respondents' evaluation. Average weighted meang of information sharing is 3.34 , indicating the average strong level of importance for construction business between construction companies and their material suppliers. Therefore, the second hyposthesis is not significantly confirmed, indicating that information sharing has not been practically applied and comprehensively in business between construction companies and their material suppliers.

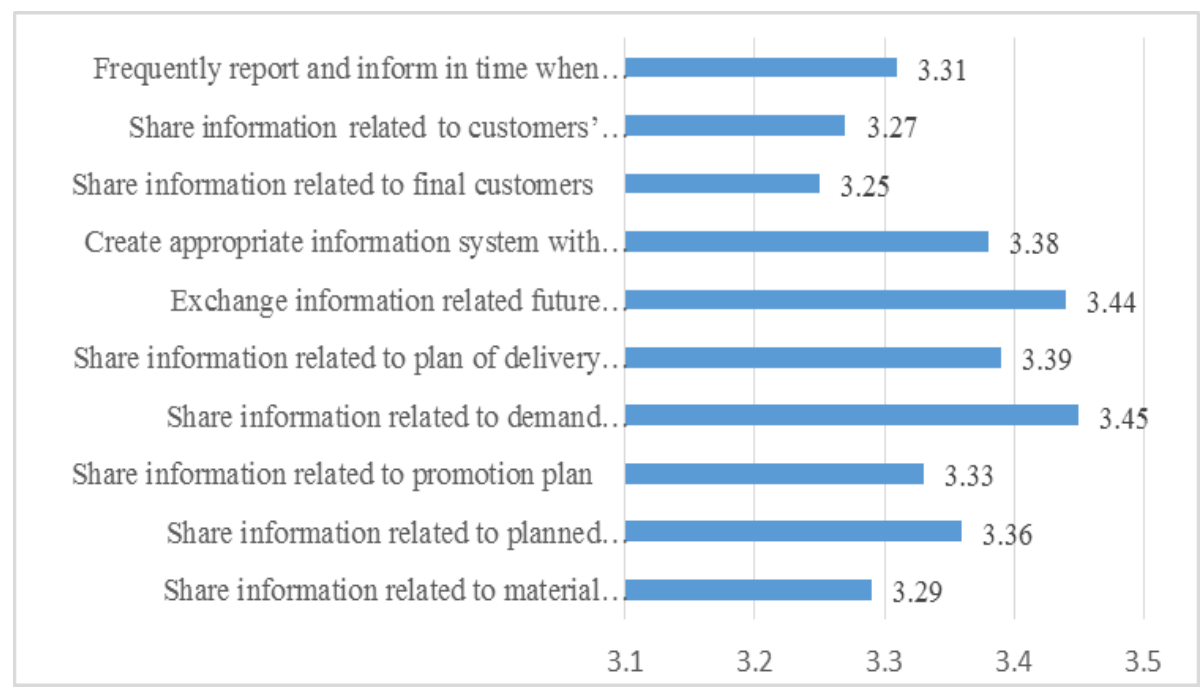

Figure 3: Important level of information sharing

Therefore, the result presented that the model of strategic collaboration with information sharing is the trend and requirement of implementing construction business operation in 21 st century with 4.0 industrial revolution for all types of construction companies. Almost construction companies need the support from partners in strategic collaboration to reduce business operation costs. However, the actual situation was not the same as expecation because of different obstacles

\section{Conclusions and Recommendations}

We used a quantitative and qualitative research method with in-depth interviews and email survey to explore the trends of strategic collaboration and activities of sharing information between construction companies and their 
material suppliers.. Almost companies are moving to higher level of collaboration with more information and resource sharing like strategic partnering or relationships. The trend of strategic alliance between construction companies and their material suppliers with information sharing and integration has been highly accepted to develop by $65 \%$ of the respondent companies. The finding indicate that companies in construction supply chain nowadays collaborate with each other through more strategic corporate agreements than only short-term contract.

With the changes of business environment and mindset, construction companies and their material suppliers have paid more attention to identifying possible activities of collaboration, formalizing their strategic agreement sand commitments, and developing collaboration options. They have increasingly concerned in sharing information and resources beyond arm's length contract or frame contract. They solved the issues related to returned materials through the operations of after-sales customer services in marketing or sales departments with quick and convenient procedures. Otherwise, many interviewers said that they have not developed a separate comprehensive strategy for collaboration with material suppliers, they have still worked with suppliers through their strategies of production and operation.. Developing strategic network for material suppliers has not been formally established in many respondent companies.

With highly complicated supply chain management, e.g. many stakeholders, many processes, and a lot of activities of construction chain, firms should select an appropriate strategy that optimal exploits both internal and external resources. Relationship between construction companies and their material suppliers should be given special resource attention in this case due to the high initial resource investments for direct involvement. The transaction cost economics can be applied here to support firms in evaluating current resources and internal capabilities for in-house operations of construction. Moreover, developing a specific construction plan (e.g. construction processes in project, stakeholder involvement, material supply plan, time schedule), and collaboration networks (e.g. relationship networks with material suppliers, main contractors, and subcontractors; transportation mode, location of handling, storage, and process, and relationships with material \& service providers) may also help firms to make decision of the involvement level. The current development of specialized material providers and increased inter-organizational collaboration in construction operations can help firms dealing with different and complicated processes of construction management more proactively and efficiently. Integrating both internal and external resources and capabilities for construction operations between construction companies and their material suppliers may be the best solution for firms in practices to reduce costs and obtain higher profitability

\section{References}

[1] Keith, O., \& Webber, M. D. (1982). Supply-chain management: Logistics catches up with strategy. In M. Christopher (Ed.), Logistics - The strategic issues (pp. 63-75). London: Chapman \& Hall 